\title{
Compositions in English: Comparing the Works of Monolinguals, Passive Bilinguals, and Active Bilinguals
}

\author{
Julia Eka Rini \\ English Department, Faculty of Letters, Petra Christian University \\ Siwalankerto 121-131, Surabaya 60236, East Java, Indonesia \\ e-mail: jerini@peter.petra.ac.id
}

\begin{abstract}
This study tries to see whether the subjects" "monolingualism" and "bilingualism" (monolinguals learning an L2 and bilinguals learning an L3) influence their study on English, especially writing. The term "bilinguals" also means "multilinguals" in this study. Bilinguals in this paper are classified into two; first, passive bilinguals who are only exposed to another local language, besides speaking Bahasa Indonesia at home, and second, active bilinguals who are exposed to and also speak other language(s) and Bahasa Indonesia at home. The findings show that the monolingual and the active bilingual are better than the passive one; the active bilingual is better than the monolingual. However, if the passive and the active bilingual are combined, the monolingual is better than the bilinguals.
\end{abstract}

Key words: writing, monolinguals, passive bilinguals, active bilinguals

Bilingualism has been people's concern since last century; this is proved by a lot of research that experts have conducted. The earlier period tends to see bilingualism as something harmful to thinking. One of the reasons that still made people question whether learning two languages were good or not was that whether learning two languages made the place for storing information full or not. Recent research shows almost no case that bilingualism brings bad effect to thinking. However, further research still needs to be conducted with lots of revision coping with the limitations of previous research so that conclusions taken from the research really deal

\footnotetext{
* Part of the data has been discussed in CONEST 5 (Conference of English Studies) held at Atma Jaya Catholic University of Indonesia on December 1-2, 2008. This article was presented at $56^{\text {th }}$ TEFLIN International Conference on December 8-10, 2009 in Batu, Malang, Indonesia.
} 
with the advantages bilinguals have over monolinguals. Previous research that tried to answer this question always used children of elementary school age. "There is almost no research on the cognitive functioning of bilinguals and monolinguals after the age of 17" (Baker, 2001, p. 135).

Therefore, this small research using the subjects of 15-30 years of age hopefully can fill the existing gap, in terms of age only. However, age is not the only variable that Baker (2001) mentions as the variable that needs to be considered in research. Other variables, such as motivation, socioeconomic circumstances, school experience, and the culture at home and in the community, the kinds of bilinguals - balanced or limitedcannot be controlled in this small research. Bilinguals in this study mean the students who use two or more languages at home. This definition is based on the one given by Romaine $(1995$, p. 12) following Mackey that bilingualism is the alternate use of two or more languages, although she does not limit the domain, at home or somewhere else. Bilinguals in this paper are classified into two; first, those who are exposed to another local language (passive bilinguals), besides speaking Bahasa Indonesia at home; second, those who are exposed to and speak other language(s) and Bahasa Indonesia at home (active bilinguals), while monolinguals are those who are only exposed to and speak Bahasa Indonesia at home. How well the bilinguals can speak the other language(s) - that should be considered in research - was not taken into consideration in this research because of the limited time and possible chance to interview all the subjects. The term "bilinguals" also means "multilinguals" in this study. The fact that all students in Indonesia also study English at school, beginning in junior high school, if not elementary school, is also ignored. This paper does not try to prove the influence of bilingualism on cognition by measuring the intelligence through IQ test either, but it tries to see whether the subjects' "monolingualism" and "bilingualism" influence their study on English, especially writing. Research has now talked about an individual learning an L3 and not only an L2. Therefore, it is not out of track if this research tries to see how different the monolinguals' works in writing (monolinguals learning an L2) compared to the bilinguals (that are learning an L3), although the variables used to label the subjects as monolinguals and bilinguals are just the languages they use or are exposed to at a limited domain, which is at home.

Writing is chosen in this research because writing is a productive skill. Hopefully, this research can say something about cognition because in 
producing something, students have to think. In trying to get the answer about the relationship of bilingualism and cognition, the following question guides the research: What differences are there in the compositions of the monolinguals and bilinguals, in terms of relevance, organization, grammar and vocabulary? Relevance in writing is whether the students' ideas are in accordance with the topic given. Organization in writing is how the students arrange the ideas systematically. Vocabulary in writing is words used to express certain concepts, ideas, and so on. Grammar in writing is structures used in combining words and phrases in sentences, tenses, and etcetera. With all the limitations given in conducting this small research, hopefully some answer about bilingualism and cognition can be shown in the area of writing, namely, the use of vocabulary and grammar to express ideas in an organized and relevant way. Mechanics is only pointed out because it is assumed that adolescents and adults subjects are familiar with mechanics in writing. Hopefully, with the limitations set in this research, this research can show whether or not there are differences between the monolinguals, passive and active bilinguals.

Hammers and Blanc $(2000$, p. 6$)$ define bilingualism as "the state of a linguistic community in which two languages are in contact with the result that two codes can be used in the same interaction and that a number of individuals are bilingual," while "bilinguality is the psychological state of an individual who has access to more than one linguistic code as a means of social communication." According to Romaine (1995, p. 12), following Mackey, bilingualism is the alternate use of two or more languages; bilingualism in her definition also includes multilingualism. Romaine's definition is used as the definition of bilingualism in this research. According to Romaine (1995, p. 12), still following Mackey, there are four aspects that should be addressed when talking about bilingualism: function, alternation, interference and degree. Functions concern the languages bilingual speakers use and the different roles they have in the individuals' total repertoire. Alternation concerns the extent to which the individuals alternate between languages. Interference concerns the extent to which an individual manages to keep the languages separate, or whether they are fused. Degree concerns proficiency. She talks about the four skills: listening, reading, speaking and writing and further says that there are some interdependencies. One would not be able to speak without developing one's listening skill. However, bilinguals can have weak productive control of one language. Romaine (1995) cited the research of Dorian of the 
Gaelic/English bilingual communities along the east coast of Sutherland in Scotland. In that area she found some speakers who had minimal control of Scottish Gaelic, but had outstanding receptive competence. Dorian refers to these speakers as "semi-speakers." Others call them 'passive' bilinguals (Romaine, 1995, p. 11).

This theory is used in classifying the questionnaires to find whether the students are monolinguals and are now studying English as the second language, or are already bilinguals and are now studying English. In this paper these already bilingual subjects in my research are divided into two groups: first, those who really use two or more languages or speak the languages, and second, those who only speak or use one language but understand another language. For example, one understands Javanese, but when people talk to him or her in Javanese, s/he does not answer in Javanese, but in Bahasa Indonesia.

In Baker (2001) the research in bilingualism and how it relates to cognition can be divided into three periods: the period of detrimental effects, the period of neutral effects and the period of additive effects. The key points (pp. 132, 160) in the chapter are as follows. Formerly, bilinguals were regarded as having a relatively lower IQ than monolinguals. Recent research showed the opposite. Research on the relationship between intelligence and bilingualism has moved from a period of investigating 'detrimental effects' to a current focus on the additive effects given by bilingualism. Additive Bilingualism occurs when the first language is appreciated while the learning of a second language occurs. A second language adds to, rather than replaces the first language; this is important for bilingualism to flourish. Subtractive Bilingualism occurs when the second language is regarded as more important than the first language, and it gradually replaces the first language. The ownership of two languages does not interfere with efficient thinking. On the contrary, cognitive advantages are gained when bilinguals have two well developed languages, particularly in divergent thinking, creativity, early metalinguistic awareness and communicative sensitivity. Research on the metalinguistic advantages of bilinguals is strong; it is said that bilinguals are aware of their languages at an early age, separating form from meaning, and having reading readiness earlier than monolinguals. This theory would be used to see whether bilinguals in the research excel those of monolinguals in their writing. 
The first research reviewed here is the research of Hernandez (2001), The Expected and Unexpected Literacy Outcomes of Bilingual Students. In this research Hernandez observes four students, one monolingual English speaker and three bilingual Spanish-English speakers. The writing events she observed include (a) the teachers' oral instructions, (b) the students' writing, (c) the student-student and student-teacher interactions, (d) the views of writing voiced by the teachers, students and parents. She used traditional qualitative research methods: participant observation, interviews and field notes. In analyzing the writing proficiencies manifested in the compositions, she used a multidimentional approach that included the content of the writing as well as its organization, sentence complexity and mechanics. I adopted the multidimentional approach of analyzing the writing texts in this paper because relevance and organization are related to students' cognition. In this paper subjects' writings were analyzed multidimentionally, using the aspects in the rating scale used to score the students' works, which include relevance and organization, vocabulary and grammar.

The second work reviewed here is Mostafa's Bilingualism and the Academic Achievement of Malay Students (2002), since this study is also about bilingualism and cognition. Her study does not find any significant relationship between the Malay students' degree of Malay-English bilingualism and their academic performance, but the study proves that being a bilingual enables a Malay student to perform better in activities that assessed his/her English language ability. This reinforces, according to her, the fact that being bilingual does have its advantages. Malay bilinguals have the advantage of having the added benefits associated with being proficient in English as a second language, namely to function more effectively as a world or global citizen and to be exposed to wider fields of knowledge associated with the use of English as opposed to having a limited, regional one associated with the use of the Malay language or Bahasa Malaysia.

The third work reviewed here is Leung's L2 vs.L3 Initial State: A Comparative Study of the Acquisition of French DPs by Vietnamese Monolinguals and Cantonese-English Bilinguals (2005, pp. 39-61). The research compares the acquisition of the Determiner Phrase (DP) by two groups of beginning French learners: an L2 group (native speakers of Vietnamese who do not speak any English) and an L3 group (native speakers of Cantonese who are also proficient L2 English users.). The 
models of theoretical second language acquisition used are FTFA (Full Transfer Full Access) and FFFH (Failed Functional Features Hypothesis). These two models are compared and their extension to L3 acquisition evaluated. The L3 group performed significantly better than the L2 group on most properties tested. Transfer in L3 acquisition does not necessarily always come from L1. This research is similar with mine in terms of subjects of the research, the monolinguals studying an L2 and the bilinguals studying an L3.

\section{METHODS}

\section{Data Collection}

The data of the subjects were taken from the questionnaires (distributed in Bahasa Indonesia) students had to fill in before doing their test. Subjects were twenty nine Intermediate 3 students of an English Course in Jakarta, Indonesia, who took their promotion test. There were two instruments used, namely one-page questionnaire made by the researcher and a writing test from the English course. The topic, directions of writing, and the scoring of the writing test were done by the teachers of the English course. The questions in the questionnaire (English version) can be seen in Appendix 1. Basically it consists of age, birthplace of the students and of their parents and of the other family members, languages used by the students when they talk to the parents and to other members of the family and also to the extended family or to other people living in the same house.

The students did Reading, Listening, Grammar, Vocabulary and Writing tests. The first four covers 70 points. Writing covers 30 points $(2 \mathrm{x}$ 15 points from the rating scale). The total score is 100 points. The test discussed in this paper is writing. The aspects evaluated include organization, grammar, vocabulary and relevance. The criteria for these aspects can be seen in Appendix 2. The rating scale and the criteria are from the English Course. The topics and the directions of the writing test were as follows:

Directions: Write a \pm 250 word argumentative essay focusing on the introductory and body paragraphs based on one of the topics. Your writing will be evaluated based on organization, grammar, vocabulary and

relevance. The topics were (1) Becoming the top student in class, (2) 
Achieving success despite physical handicap, (3) Can a woman be successful in a male-dominated field? (4) Free education for all children aged 7 to 14 years old.

\section{Data Analysis}

The questionnaires were classified based on the language(s) the students are exposed to and the language they use in speaking to other people living in the same house. From the questionnaires, subjects can be classified into three groups. The first group (henceforth group A) is 6 monolingual students, who are exposed only to Bahasa Indonesia at home and also speak only Bahasa Indonesia at home. They are between 16-27 years old, one student is 35 years old. The second group (henceforth group B) is 11 students who are exposed to a regional language at home - either her/his parents or other family members speak one regional language — but the students only use Bahasa Indonesia when talking to them (passive bilingualism). Their ages are between 15-26 years old. The third group (henceforth group C) is 12 students who are exposed to other languagessome are only exposed to and speak one regional language, some are also exposed to and speak foreign language(s), such as Japanese, English and Korean, besides a regional language - besides Bahasa Indonesia (active bilingualism). Their ages are between $15-30$ years old.

The following procedures were applied in analyzing the test scores: first, writing test scores obtained by the students were classified according to the group, A, B, C. Second, writing test scores of each group were ranked from high to low and also other scores, such as Others (listening, reading, usage and vocabulary) and also oral test.

Third, three tests were taken from each group: the highest score, the borderline (the score was 14) and the lowest. For a writing to be good, 14 was supposed to be the lowest score, if it was seen from the criteria of the rating scale of writing (taking the lowest score of the middle part; see the rating score in Appendix 2). Below 14, it was not good. If there were more than one student who got the same lowest scores, the work of the student who got the lowest total scores was taken. The same thing was done with the highest score and the borderline. If there were two students who got the same highest scores in writing, the student with the highest total score was taken. If there were more than one student who got the borderline score, the one who got the highest borderline total score was taken. 
Fourth, the scores from the three students from each group, the mean (M) of writing and the total scores of (Writing and Others) of each group was put in Table 1. $M=$ total score: total number of students.

Fifth, these nine students then were grouped as the highest, the borderline and the lowest score (from groups A, B, C). The nine students' compositions were then compared: the three highest students, the three borderline students, and the three lowest students.

\section{FINDINGS AND DISCUSSION}

The Scores, the Means, the Topics Chosen in Each Group, and the Students' Scores Taken To Be Analyzed

In Group A (monolinguals), out of six students, four students (67\%) got $\geq 14$. The other two students got 8 . Five students chose the first topic, 'Becoming the top students in class'. One student chose the last topic, 'Free education for all children aged 7 to 14 years old'. In Group B (passive bilinguals), out of eleven students, three students (34\%) got $\geq 14$. Two students got 12 , one student got 10 , and the other five students got 8 . Nine students chose the first topic, 'Becoming the top students in class'. Two students chose the last topic, 'Free education for all children aged 7 to 14 years old'. In Group C, out of twelve students, ten students (82\%) got $\geq 14$. The other two students got 12. Nine students chose the first topic, 'Becoming the top students in class'. Two students chose the last topic, 'Free education for all children aged 7 to 14 years old'. One student chose the third topic, 'Can a woman be successful in a male-dominated field?'

Below is the mean of each group and the scores of the nine students' work that are analyzed.

Table 1. The Means of Scores of Writing and the Means of Total Scores of Each Group

\begin{tabular}{cccccc}
\hline Group & $\begin{array}{c}\text { Mean of } \\
\text { writing }\end{array}$ & $\begin{array}{c}\text { Mean of total The highest } \\
\text { Scores }\end{array}$ & score & The borderline & The lowest \\
scores & score \\
\hline A & 16 & 61.3 & 26 & 14 & 8 \\
B & 13.7 & 55.4 & 24 & 14 & 8 \\
C & 17 & 59.4 & 24 & 16 & 12 \\
\hline
\end{tabular}


Table 1 shows that the scores of the borderline students and the lowestscore students are below the mean in each group, except group B. The mean scores of writing of group A and C are nearly the same, but Group B's is different and a little bit below the borderline score (14). Group A student in the highest score group (the monolingual group) gets the highest score and the students in the bilingual groups (B and C) get the same scores, that is, below the highest score of the monolingual group. If it is seen from the scores only, the mean score of writing of group $\mathrm{C}$ was the highest and slightly below was group $\mathrm{A}$, which means that nearly all students (82\%) in those groups were above borderline scores (14).

The mean of total scores shows that the monolingual (group A) mean of total score was higher than the other two, but the active bilingual (group C) mean of total score was higher than the passive one (group B). Temporary conclusion, only obtained from scores and means, is that monolinguals and active bilinguals seemed to excel the passive bilinguals. This still needs to be checked with the analysis of students' works.

\section{Analysis of Students' Work}

For the sake of convenience, the summary of students' work is put in the Table 2.

\section{Table 2. Summary of Analysis of Students' Work}

\begin{tabular}{|c|c|c|c|c|}
\hline $\begin{array}{l}\text { Aspects of } \\
\text { Writing }\end{array}$ & Group & $\begin{array}{l}\text { The highest } \\
\text { group }\end{array}$ & $\begin{array}{c}\text { The borderline } \\
\text { group }\end{array}$ & The lowest group \\
\hline \multirow[t]{3}{*}{$\begin{array}{l}\text { Relevance } \\
\text { and } \\
\text { Organization }\end{array}$} & A & $\begin{array}{l}\text { Relevance and } \\
\text { organization } \\
\text { are good }\end{array}$ & $\begin{array}{l}\text { - no title } \\
\text { - Development of } \\
\text { ideas are OK } \\
\end{array}$ & $\begin{array}{l}\text { - } \text { Relevance is OK } \\
\text { - Ideas are repeated } \\
\text { or overlapped }\end{array}$ \\
\hline & $\mathrm{B}$ & $\begin{array}{l}\text { Relevance and } \\
\text { organization } \\
\text { are good }\end{array}$ & $\begin{array}{l}\text { - There are attempts } \\
\text { to organize ideas }\end{array}$ & $\begin{array}{l}\text { - "agree" in the last } \\
\text { paragraph is not } \\
\text { supported } \\
\text { adequately } \\
\text { - Ideas are not clear } \\
\text { - Sentence meaning } \\
\text { is not clear }\end{array}$ \\
\hline & $\mathrm{C}$ & $\begin{array}{l}\text { - Relevance and } \\
\text { organization } \\
\text { are good } \\
\text { - no title }\end{array}$ & $\begin{array}{l}\text { - no title } \\
\text { - unnecessary } \\
\text { supporting } \\
\text { sentences }\end{array}$ & $\begin{array}{l}\text { - Relevance and } \\
\text { organization of } \\
\text { ideas are better } \\
\text { than A \&B. } \\
\text { - "disagree" is not } \\
\text { supported }\end{array}$ \\
\hline
\end{tabular}




\begin{tabular}{|c|c|c|c|c|}
\hline $\begin{array}{l}\text { Aspects of } \\
\text { Writing }\end{array}$ & Group & $\begin{array}{l}\text { The highest } \\
\text { group }\end{array}$ & $\begin{array}{l}\text { The borderline } \\
\text { group }\end{array}$ & The lowest group \\
\hline \multirow[t]{3}{*}{$\begin{array}{l}\text { Vocabulary } \\
\text { and Grammar }\end{array}$} & A & $\begin{array}{l}\text { - Few grammati- } \\
\text { cal mistakes } \\
\text { - gerund is } \\
\text { obvious } \\
\text { - "prestations" } \\
\text { for achievemen }\end{array}$ & $\begin{array}{ll}\text { - } & \text { article } \\
\text { - Grammatical } \\
\text { errors do not } \\
\text { interfere meaning }\end{array}$ & $\begin{array}{l}\text { - double or no verb } \\
\text { - Meaning of } \\
\text { sentences is not } \\
\text { clear }\end{array}$ \\
\hline & B & $\begin{array}{l}\text { - Wrong tense, } \\
\text { future instead } \\
\text { of past } \\
\text { - other gramma- } \\
\text { tical errors do } \\
\text { not influence } \\
\text { readers' } \\
\text { Comprehensior }\end{array}$ & $\begin{array}{l}\text { - wrong words, (1) } \\
\text { preservation for } \\
\text { perseverance, (2) } \\
\text { determination } \\
\end{array}$ & $\begin{array}{l}\text { - } \text { no verb } \\
\text { - Meaning of } \\
\text { sentences is not } \\
\text { clear and hampers } \\
\text { understanding } \\
\text { - phrases }\end{array}$ \\
\hline & $\mathrm{C}$ & $\begin{array}{l}\text { - Some clauses } \\
\text { are still found }\end{array}$ & $\begin{array}{l}\text { - Some sentences } \\
\text { are not clear } \\
\text { - Grammatical } \\
\text { errors influences }\end{array}$ & 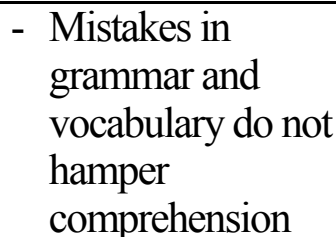 \\
\hline
\end{tabular}

Students' work taken to be analyzed is a representative of students' scores (highest, borderline, lowest) since the scoring is generally based on three parts (see appendix 2): high, mediocre, low. The analysis of the students" work is based on the criteria of the rating scale: relevance and organization, then vocabulary and grammar. Examples are given in the discussions below to make the discussion clearer. The discussion is divided into three parts: the highest, the borderline, and the lowest.

\section{The three highest students}

The students' compositions in this group are relevant to the topic they choose and they can organize the ideas well enough. Grammatical errors are underlined; sentences that are not clear are in italics. Letters in bold are errors in spelling and mechanics. Letters in bold and underlined are lexical errors.

The student of group A translates the Indonesian word prestasi into "prestations." This is obviously taken from L1, an Indonesian word "englishized." There are also grammatical mistakes but they are not severe 
enough to cause the readers to comprehend their work. The student of group B uses the word "determination" wrongly and also uses the wrong tense, future tense instead of past tense in recounting his experience as it can be seen below:

... I became the top student in class when I was in elementary school. That was the most exciting moment in my life.

First, I will get many friends, because my friends will ask me about the lesson that they don't understand. I understand the lesson, so I can teach my friends. Second, my parents will happy if their children get a high score in school. When my parents happy, whatever I want, they will give it to me. Other benefit of become the top student in class is I will get more respect from my friends and teacher. But now, in SMA, I have never been become the top student in class.

Apart from this wrong tense, other grammatical errors do not block readers' comprehension.

Group C student still writes clauses as it can be seen below:

Especially, if you don't understand about something that the teacher said. And finally, must be active. Don't be a passive person because if you were passive, you would lost the chance to be the top student in the class. The conclusions, if you want to hard work, it's not hard to be the top student in the class. Because to be the top student need hard work.

Some grammatical errors are still there, for example, there is no subject or no verb; the student uses infinitive instead of past tense.

\section{The three borderline students}

Group A student can organize ideas, although concrete actions in the examples are not yet given.

the first thing we must do is study hard. We wont became successful if we dont do that. With study hard we can know how to get the best score in our exam, so we wont have a difficulty in our exam and we will get the best score easily. therefore, our laziness. 
Development of ideas is still abstract, talking about consequences of studying hard and not studying hard; however, ideas are still relevant.

Grammatical and lexical errors are there, but they do not cause a problem, as it can be seen below:

If we never get fail, we will never know how to get successful, therefore dont give if we fail in many ways, because it will bring us to the right way and we will be succeful student, and the last thing is pray. After we already do study hard and learn from our failure, we shouldn't forget to pray. Because everything will not happend if god doesn't bless for us. its not imposible to reach it if we do the three keys. So, why dont you do that three keys...

Besides errors on grammar and vocabulary, there are also many errors on mechanics as it can be seen in the quotations above.

Group B student attempts to organize and support their ideas, but uses wrong key words, such as "preservation" for perseverance and "determination" which is not clearly related to studying hard as it is shown in the examples from the student's work below:

Becoming the top student in class, they must have to do something such as determination, preservation and supported by their parents. If they want to be the top student in class, they must have to do something. First, the student must have determination. Because determination is important for the top student: Such as study hard, follow many course like english course, Math course etc. Secondly, the student must have preservation. Preservation is important because it can support too. And finally, Supporting by parents can also support the education's student. The parents will give it everything, like pay their school, their many course.

So, becoming the top student in class, they must have to do something such as determination, preservation and supported by their parents. From of all can make their dream come true like to be the top student in their class.

The grammatical errors do not really prevent readers to comprehend the content of writing.

One student's work (from Group C) is not really relevant with the task and the organization of ideas is very poor. The first paragraph already 
shows the facts when "parents" and "being smart" are included in the paragraph.

Becoming the top student is our dreaming. And of course, our parents really love us. It can happen with every person in the world. Basically, every person is smart in the world. But it can not be useful if you didn't study hard.

The third paragraph in the composition also shows irrelevant supporting sentence.

But, we can not do that without our parents support. Parents, not only give the supports, also give the advice to their children. As a teenagers we must positive think with our work. If we failed in something condition, we must raise up and try it again. Because successful will begin from our failed. Not only that, but also our patient is need for to do our problems. And if you success, you must do your better again. So, as a student when changing to adult, we must to faced our problems with calm down our mind and our emotional.

There are also grammatical errors and some clauses do not have clear meaning such as "So, as a student when changing to adult,..." "But, we study it not with along time. Because it can make us bored." These clauses are certainly ambiguous.

\section{The three lowest students}

The students in groups A and B have more grammatical mistakes in their work. For example, group A student writes sentences with no main verbs, just auxiliaries or double main verbs.

In class, we can top student rank. If we can top student rank we must know how the top student rank. Although not easy to be top student top student in class, we must do study hard if we can the top student in class. Sometimes we must do study hard everywhere...

and I am sure that this is a mistake, not an effort to emphasize the meaning of the sentence. Gerund is also a problem "such as read book in the library, study together with friend, etc." In the clause "try homework be your self", 
probably the student wants to use the word "by" instead of "be," but this mistake certainly hampers readers' comprehension.

Organizing ideas is not done neatly. "do more exercise everywhere" and "don't play anything" and we "can top student rank" are repeated over and over again; the same sentences are in the first, second and third paragraphs. Actually the student just has these three ideas in mind and the ideas are not supported, but only written repeatedly in the same sentences.

Group B student also makes grammatical mistakes and the meaning of sentences is not clear, for example, in the first sentence of the composition "Every children in every country should be a education." Meaning is also not clear in the second sentence "We must pay before we can learn in there. But not every people do there." It is also not clear in these ones " $a$ children in Indonesia nothing drop out from they school." "And can reduce generation before them."

This sentence does not have a verb: "Actually, education more important than anything." This one is a phrase: "Surely, knowledge who they have different." In this sentence "They parents think if school only spent they time" I think the verb meant to be used is "waste" (school only wastes their time.) In these sentences the student use wrong parts of speech of words. "They can ... or a working for money in the employee. They will not hunger"

The following is mistakes in spelling:

"education in school, familie or their life area. Perhabs, ...I think free education can help a chil who life in a poor family education formal also not cheap. Why they parents didnt have money?"

Between education and formal, there should be period. Another example: they chil want to school. they didnt pay their school. thirdly ...

Group C student is much better in terms of organizing the ideas, as it can be seen in the composition below, although in the second paragraph the topic sentence "we must support the government" is not adequately supported. "I'm disagree" is also not well-supported and does not have any reference (disagree to what, it is not explained).

Many children in Indonesia cannot be a student because problem of economic their parents. The children poor have drop out from the 
school because they can't payed to studying in the school, and the children's poor must be working in slum area to get some money with searches the plastics for the sell and they have money or they singing in the street or selling the newspaper everyday. The government should be concern and care to the children poor with give the free education for all children aged 7 to 14 years old. We can optimise and believe that the children have the education for 9 years old, they will be more better life than before.

We must supported the government to preparing and planning about free education for all children in Indonesia, because it can benefit to our country. The firstly, I'm disagree about this and always supported the planning government. We hopefully the president really seriously and concern to focus gave the children of free education. Secondly, with the free education for all children, we cannot to seeing the children working in the street to get money because their parents no have enough money to pay children's go to school. Thirdly, the parents can be working to get money for need life their family everyday and can be life more easily because the children give the education and knowledge to better life and their future. And someday the paren't and we all can proud the children because they have destination in the future.

We believe that the government give the better solution to free education for all children, the people poor and children poor can be successful and becoming the top student.

Although many things are not adequately supported, more or less readers can understand what the student wants to say.

This student can also construct complete sentences although there are grammatical mistakes, for example, "the people poor and children poor," "we all can proud the children," "I'm disagree".

Vocabulary in "We can optimise and believe that the children have the education for 9 years old, ... they have destination in the future" But the mistakes in grammar and vocabulary do not hamper readers' comprehension seriously.

The findings can be summarized as follows:

1. Grammatical and lexical mistakes occur in every group, whether the groups are classified based on the language(s) they speak at home$\mathrm{A}, \mathrm{B}$, and $\mathrm{C}$ - or those based on the scores they get - the highest, the borderline and the lowest. 
2. From table 2, in terms of organization of ideas, nothing can be said about which group is better than the others. Although group $\mathrm{C}$ of the lowest-score group is better than group A and B in the lowest-score groups, the borderline student of group $\mathrm{C}$ also writes irrelevant task and has poor organization in the composition compared to $\mathrm{A}$ and $\mathrm{B}$ in the borderline groups.

3. Mechanics is still a problem in the borderline and the lowest (although not all students have this problem), for example: there is a problem of capitalization in the beginning of the sentence; abbreviated "not" should be written "n't", but it is not done that way. Students write "wont" instead of "won't" (apart from the rule that abbreviation is not encouraged in a formal composition).

4. If it is seen from the writing score and the mean score, both the mean of the writing scores and of total scores, and the percentage of students who get $\geq 14$ (34\% students of Group B get $\geq 14$, group A 67\%, group C $82 \%$ ), the monolinguals and active bilinguals are better than the passive bilinguals; analysis of students' work, however, does not show that.

5. If groups $\mathrm{B}$ and $\mathrm{C}$ are combined and labeled under bilingual, there are several points that are quite interesting. In terms of the number of students who get $\geq 14$, only $56.5 \%$ bilingual students get $\geq 14$ and this is below the monolingual $(67 \%)$. The mean of the total score of the bilingual (57.4) is also below the monolingual (61.3). The mean score of writing of the bilingual (15.85) is also lower than the monolingual (16). It can be concluded that the monolingual is better than the bilingual.

\section{CONCLUSION}

If the scores, the mean score of writing, and the percentage of students that get above the borderline score of writing are compared, group $\mathrm{C}$ (the active bilingual) is better than the other two groups; however, the mean score of the total score is slightly lower than the other two groups. The monolingual group (group A) is much better than group B, in the mean score of writing, the total score, and the percentage of students that get above the borderline score of writing - A is $67 \%$ and $B$ is only $34 \%$. This shows that both the monolingual and the active bilingual groups are better than the passive one; the active bilingual is better than the monolingual. 
However, if the bilingual groups are combined (B and C), the monolingual is still better.

However, comparing the works of groups A, B, and C, in the highest student group, no significant differences are found in relevance and organization of ideas, grammar and vocabulary. Comparing the works of groups $\mathrm{A}, \mathrm{B}$, and $\mathrm{C}$, in the borderline student groups, in terms of organization of ideas, group $\mathrm{C}$ also writes irrelevant task and has poor organization in the composition compared to $\mathrm{A}$ and $\mathrm{B}$ in the borderline groups. Comparing the works of groups $\mathrm{A}, \mathrm{B}$, and $\mathrm{C}$, in the lowest student groups, group $\mathrm{C}$ students in the lowest group are better than group $\mathrm{A}$ and $\mathrm{B}$. Although group $\mathrm{C}$ in the lowest group is better than $\mathrm{A}$ and $\mathrm{B}$, this fact does not prove that active bilingual (group $\mathrm{C}$ ) is better than the passive one (group B) and the monolingual (group A), because students in the borderline student group of group $\mathrm{C}$ wrote irrelevant task and had poor organization. If bilingualism were really significant in this research, then group $\mathrm{C}$ would be consistently better than the other two.

Whether or not bilingualism influences cognition, further research needs to be conducted with more subjects, involving more considerations on other aspects, such as motivation, types of bilingualism (balanced or not), length of composition, languages used outside homes, what languages used to discuss what topics, socioeconomic status of the subject etc.

Since grammar and vocabulary are also evaluated in writing, it is good to see how they are related with the ones in the test classified in "Others", which is a multiple-choice test because "Others" are a linguistic manipulation test, while writing is not. Further findings and conclusion can probably be obtained if more aspects are taken into consideration.

\section{REFERENCES}

Baker, C. (2001). Foundations of bilingual education and bilingualism ( $3^{\text {rd }}$ ed.). Clevedon: Multilingual Matters.

Hamers, J. F., \& Blanc, M. H. A. (2000). Bilinguality and bilingualism. Cambridge: Cambridge University Press.

Hernandez, A. C. (2001). The expected and unexpected literacy outcomes of bilingual students [Electronic version]. Bilingual Research Journal, 25(3), 251-276.

Leung, Y. I. (2005). L2 vs. L3 initial state: A comparative study of the acquisition of French DPs by Vietnamese monolinguals and Cantonese-English bilinguals. Bilingualism: Language and Cognition 8(1), 39-61. 
Mostafa, N. A. B. (2002). Bilingualism and the academic achievement of Malay students. International Conference IPBA on September 24-26, 2002. Retrieved October 7, 2008, from http://apps.emoe.gov.my/ipba/rdipba/cd1/ article134.pdf.

Romaine, S. (1995). Bilingualism (2 ${ }^{\text {nd }}$ ed.). Oxford: Blackwell. 